\title{
Effects of North Carolina's mandatory safety belt law on children
}

\author{
Lewis H Margolis, Jennifer Bracken, J Richard Stewart
}

\begin{abstract}
Objectives-To assess the effect of the North Carolina law mandating that all front seat passengers use a safety belt on children 4 through 15 years of age.

Methods-North Carolina collision reports, completed by local police or the state highway patrol for crashes with greater than $\$ 500$ worth of damage, were analyzed using time series analysis on the monthly percentage of deaths and serious injuries between January of 1980 and February of 1994.
\end{abstract}

Results-Following the 1985 implementation of the law, children 4 to 15 years of age experienced a $42 \%$ decline in deaths and serious injuries.

Conclusions-The mandatory safety belt law in North Carolina has been associated with a decline in deaths and serious injuries. Additional research is needed to assess the seat belt behaviors of this age group as well as the specific effects of seat belt use using outcome measures more precise than those available in police crash reports.

(Injury Prevention 1996; 2: 32-35)

Keywords: seat belt law, child motor vehicle passenger safety.

Child restraint devices (CRDs), designed to reflect the anatomic characteristics of young children in crashes, have significantly reduced the morbidity due to car crashes. ${ }^{1-3}$ Following the successful implementation of child restraint programs in every state, many states have mandated the use of safety belts for occupants of all ages. Unlike CRDs, safety belts, designed for adults, do not take into account the anatomic characteristics of children particularly those under the age of 10 years. While many studies have documented the effectiveness of mandatory safety belt laws for adults, ${ }^{45}$ there is a paucity of research on the effects of these laws on children, particularly young children who have graduated from CRDs into safety belts.

In July 1985, the North Carolina Child Passenger Safety Law was expanded in two ways. First, the age at which children were required to use a CRD was raised from 1 to 2 years. Second, children from 3 through 5 years of age were required to use a safety belt or CRD, regardless of seating position. In October 1985, the North Carolina Safety Belt Law was enacted, requiring all front seat passengers to use a safety belt. Using data for the 66 months before and 104 months after the implementation of the July law (affecting 4 and 5 year olds) and the 69 months before and 101 months after the implementation of the October law (affecting all children), the purpose of this article is to examine the effects of these laws on children 4 through 15 years.

When properly used, automobile safety belts reduce the risk of death or serious injury in motor vehicle crashes by at least $40 \% .{ }^{67}$ 'Proper' use for children, however, is problematic due to several anatomic features. ${ }^{8}$ First, the lapbelt is designed to fit between the upper thigh and the iliac crests of the pelvis, but the pelvis is not sufficiently developed to anchor the belt until the age of 9 or 10 years. Consequently, serious abdominal injuries may result as the belt rides up over the iliac crests. Second, depending on the height of the child, the shoulder belt may be improperly positioned for example above the chest on the neck or face.

Several hospital based studies have examined the effects of safety belts on children. Agran et al reviewed the injuries associated with safety belt use in a sample of 177 children from birth through 14 years who were treated in emergency rooms after motor vehicle crashes. ${ }^{9}$ The emergency rooms were part of a nine hospital monitoring system in one southern California county. Only $17 \%$ of the children were uninjured. Of the injured children between 10 and 14 years, $7 \%$ sustained a maximum injury severity score (MAIS) of greater than 1. In contrast, of the injured children between the ages of 4 and 9 years, $18^{\circ}{ }_{1}$ sustained a MAIS of greater than 1, confirming that the use of safety belts has different effects on younger and older children.

Osberg and Di Scala compared the injuries of 123 belted children (aged 4 to 14 years) to 290 unbelted children using data collected for the National Pediatric Trauma Registry, Phase II.$^{10}$ Unrestrained children had higher rates of mortality $(4.5 \% \vee 2.4 \%)$, severe head injury, and general severity. It is noteworthy, however, that none of these findings achieved statistical significance.

Hall and Stewart used statewide crash data to examine the effects of North Carolina's mandatory safety belt law. ${ }^{11}$ Beginning in July 1985 , children under the age of 6 years were required to use a safety belt, with CRD use required for those under age 3. In October 1985, belts were required of all front seat passengers regardless of age. Using before and after comaprisons of proportions, Hall and Stewart reported fatal or serious injuries among 2-5 year old children declined by $15.4 \%$ from the period before to the period after the law. Some proportion of that decline, however, was due to the use of CRDs. What is noteworthy for children 6-15 
years is that the proportion of fatal and serious injuries declined by only $5 \cdot 4 \%$. The broad category of 6-15 years masks the effects of the law on the younger children for whom safety belts are not anatomically optimal. Furthermore, simply comparing injury rates in three time periods is not the most sensitive method.

In summary, a limited number of studies suggest that mandatory seat belt laws have had a less than intended effect on young children. Longitudinal statewide crash reports provide the opportunity to document the impact of safety belt laws on children who need anatomically appropriate protection in motor vehicles.

\section{Methods}

SOURCE OF DATA

The data for this study come from the North Carolina collision reports. These reports are completed by local police or the state highway patrol for crashes with greater than $\$ 500$ worth of damage. The damage amount for inclusion in these data has gradually been adjusted upward. Before 1983, crashes with greater than $\$ 200$ damage were included and soon only crashes with greater than $\$ 1000$ damage will be included, minimizing the artificial inflation of the number of individuals included in the data set. For this study, the following variables were extracted from the 109 variables collected in the collision reports: age of child occupants, seating position, month and year of the crash, severity of the crash, and vehicle size. Also extracted was the injury class for the children and for the adult driver, using the $\mathrm{KABCO}$ scale, where ' $K$ ' represent a fatal injury, ' $A$ ' indicates heavy bleeding or other injury serious enough to be incapacitating for 24 hours, ' $B$ ' represents any other injury apparent at the scene, ' $C$ ' indicates minor pain or momentary loss of consciousness, and ' $O$ ' indicates no injury. Popkin et al have reported that this system is a valid measure of injury severity. ${ }^{12}$

EXPOSURE TO SAFETY BELTS

Self report of safety belt use is generally invalid. Summaries of collision data in North Carolina routinely report belt use in greater than $80 \%$ of these involved in crashes. ${ }^{13}$ Instead of using the collision report of belt use as the measure of individual exposure to safety belts, this study uses an ecologic measure of exposure based on an overall increase in adult belt use from $20 \%$ to over $60 \%$, following the 1985 law. $^{13}$

\section{STUDY POPULATION}

The target population was chilren in an age group where their anatomical characteristics are most unsuited to safety belts. Three age stratifications for children were used: 4 and 5 years, 6 through 10, and 11 through 15 . Three years of age could have served as the lower limit, because the child law includes children up to that age. However, recent observations indicate that $37 \%$ of 3 year olds still use CRDs, compared with only $13 \%$ of 4 year olds. ${ }^{14}$ Since over a third of the 3 year olds are using CRDs, the effects of the safety belt law would be overstated if they were included in the analysis. The sample was further restricted to front seat passengers, because belts are required only for these passengers. In summary, study cases included all front seat passengers involved in crashes recorded in the collision reports.

To control for crash circumstances, the sample was restricted to drivers involved in crashes with child passengers. Specifically, adults and children driving together experience similar crash factors, such as the use of alcohol, driving conditions, and speed that could also influence whether safety belts, not to mention the law, are effective. ${ }^{15}$

\section{STUDY DESIGN}

For each of the four occupant age groups, the per cent of all crash-involved occupants in that age group who were fatally $(\mathrm{K})$ or seriously (A) injured was determined monthly. Each monthly series consisted of 170 observations from January 1980 through February 1994. The data were initially aggregated at the monthly level to provide the opportunity to examine short term changes over time. Quarterly data for the 4 and 5 year old occupants were also analyzed. The per cent of serious and fatal injuries was chosen as the measure of effect since this quantity would be expected to decrease with increasing use of occupant restraint systems. The per cent, should, moreover, be relatively unaffected by changes in population size, miles driven, and other factors that might result in changes in total numbers of crashes or in numbers of serious and fatal injuries.

In this quasi-experimental design, interrupted time series analyses were used to summarize the data and to characterize changes coincident with the legislative changes. Since observations over time often exhibit significant serial correlation, statistical methods that assume independent observations are inappropriate. Data series corresponding to each of the four occupant age groups were analyzed separately. Note that the intervention point for the children under the age of 6 was July 1985, while for the other three age groups the intervention point was October 1985.

Structural time series models were fitted to the data series using the software package STAMP (Structural Time Series Analyzer, Modeller, and Predictor).$^{16}$ Structural models that may include stochastic trends, seasonal factors, and the intervention effects are formulated in state space form and estimated via the Kalman filter. ${ }^{17}$ This type of model was used by Harvey and Durbin in their landmark study of the effect of seat belt legislation on British road casualties. ${ }^{18}$

Models for two types of intervention effects were considered: (1) a step change in the level of the series at the point of intervention and (2) a change in the slope of the series beginning at the intervention point. The step in the level of the series refers to the change in the fitted trend for per cent killed and seriously injured before and after the intervention - that it, the implementation of the law. The change in slope tests the effect of the implementation of the law on 
the slope, whether or not there has been a change in the fitted trend. In summary, eight models were constructed - four age groups for each of the two measures of effect.

\section{Results}

During the 170 months under study, 3324 children 4 to 15 years died or sustained serious injuries as motor vehicle passengers on North Carolina roadways. Of these children, $11.7 \%$ were $4-5$ years of age, $24.8 \%$ were $6-10$ years, and $63.6 \%$ were $11-15$ years. Of the drivers of those motor vehicles, 4774 were killed or seriously injured.

The table shows the components of the models and the estimated intervention effects from both models. Both models reveal statistically significant intervention effects for the 4 and 5 year old children. The change in slope model, however, fit the data somewhat better. Moreover, in a model containing both a shift in level and a change in slope, only the change in slope parameter was significant (estimate $=-0.0118, t=-2 \cdot 152, \mathrm{p}=0.016$ )
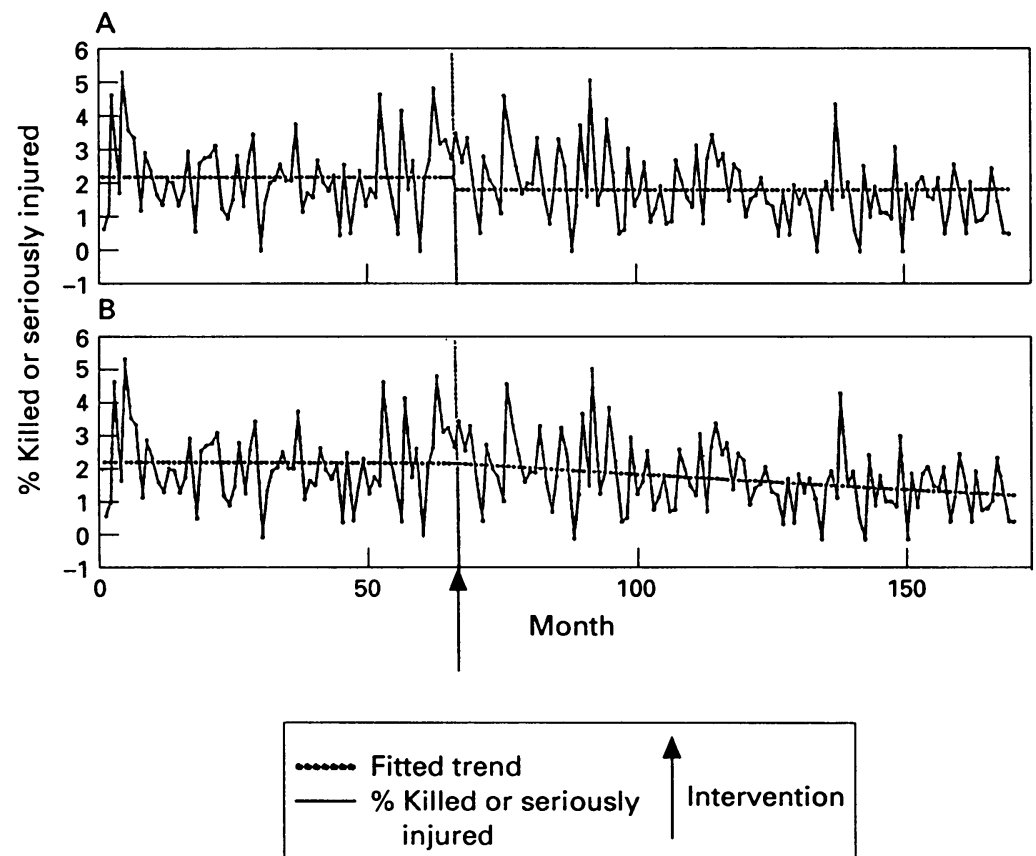

( A) Step change in level fitted trends and ( $B$ ) change in slope fitted trends for per cent of 4 and 5 year old children killed or seriously injured.
The estimated shift in level from the first model represented a $16.7 \%$ decrease after the intervention. With the change in slope model, the level decreases gradually after the intervention. However, by February 1994 (the last data point in the series), the fitted level had decreased to $1.31 \%$ from the value $2 \cdot 26 \%$ in June 1985 (the last month before the intervention), a net decrease of $42 \%$. The figure shows the data points ( $\%$ killed and seriously injured) with the step change for the fitted trend (A) and the change in slope (B) at the intervention for children aged 4 and 5 years. In results not shown, the quarterly analyses produced similar findings.

For the other three data series for the older children and adults, only the change in slope models were statistically significant (table). Overall decreases in level from the last preintervention point (September 1985) to February 1994 were $42.5 \%$ for the $6-10$ year old children, $45.4 \%$ for the $11-16$ year olds, and $43.9 \%$ for the adults.

\section{Discussion}

Following the successful implementation of a child restraint law, North Carolina adopted a safety belt law for all front seat occupants. These laws have reduced deaths and serious injuries for adults and children, but the mechanisms vary among the age groups. For children aged 4 and 5 years the law was associated with a change in the level of the series, suggesting an immediate impact on the behavior of adults responsible for assuring that children use safety belts. For the other children (and the drivers), the change from the predicted level of deaths and serious injuries was reflected only in a change in the slope of the series. This suggests a more gradual change in behavior due to the law, perhaps associated with other interventions such as public education campaigns, periodic intense enforcement efforts, or changes in social norms regarding safety belt use. Although the gradual change in the slope suggests that a significant change might have been noted at other points along the series, other clearly time delimited interventions likely to have an impact on crash related injuries had not been implemented.

The marked decline for the youngest children is noteworthy because these are the children for whom safety belts are anatomically least

Effects of the safety belt law on $(A)$ step change in level and $(B)$ change in slope of the fitted trend of monthly killed or seriously injured

\begin{tabular}{|c|c|c|c|c|c|c|c|c|c|c|}
\hline \multirow[b]{2}{*}{$\begin{array}{l}\text { Age } \\
\text { (years) }\end{array}$} & \multicolumn{5}{|c|}{ Model components } & \multicolumn{5}{|l|}{$\underline{\text { Estimates }}$} \\
\hline & $\begin{array}{l}\text { First } \\
\text { level }\end{array}$ & $\begin{array}{l}\text { Stochastic } \\
\text { level }\end{array}$ & $\begin{array}{l}\text { Fixed } \\
\text { slope }\end{array}$ & $\begin{array}{l}\text { Stochastic } \\
\text { slope }\end{array}$ & $\begin{array}{l}\text { Trigonometric } \\
\text { seasonals }\end{array}$ & $\begin{array}{l}\text { Before } \\
\text { intervention } \\
\text { estimate }(\%)\end{array}$ & $\begin{array}{l}\text { After } \\
\text { intervention } \\
\text { estimate }\left({ }_{0}{ }_{0}\right) \dagger\end{array}$ & $\begin{array}{l}\text { Intervention } \\
\text { estimate }\end{array}$ & $S E$ & p Value \\
\hline \multicolumn{11}{|c|}{ (A) Step change in level } \\
\hline $4-5$ & $\times$ & & & & & $2 \cdot 19$ & $1 \cdot 82$ & -0.3662 & $0 \cdot 1687$ & $0 \cdot 016$ \\
\hline $6-10$ & & $x$ & & & $x$ & $\mathrm{NA}$ & $\mathrm{NA}$ & 0.0896 & $0 \cdot 2803$ & 0.375 \\
\hline $11-15$ & & $\times$ & & & & NA & $\mathrm{NA}$ & -0.3544 & 0.2925 & $0 \cdot 114$ \\
\hline $\begin{array}{l}16+ \\
\text { (B) Chan }\end{array}$ & 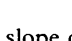 & $\times$ & & $\times$ & $x$ & NA & NA & -0.3307 & $0 \cdot 2621$ & $0 \cdot 104$ \\
\hline \multicolumn{11}{|c|}{ (B) Change in slope of fitted trend } \\
\hline $6-10$ & & $x$ & & & $\times$ & $\begin{array}{l}2 \cdot 26 \\
2 \cdot 40\end{array}$ & $\begin{array}{l}1.31 \\
1.38\end{array}$ & $\begin{array}{l}-0.0091 \\
-0.0101\end{array}$ & $\begin{array}{l}0.0023 \\
0.0016\end{array}$ & $\begin{array}{l}<0.0001 \\
<0.0001\end{array}$ \\
\hline $11-15$ & & $x$ & & & & 3.37 & 1.84 & -0.0152 & 0.0029 & $<0.0001$ \\
\hline $16+$ & & $x$ & & $x$ & $x$ & $4 \cdot 10$ & $2 \cdot 30$ & -0.0323 & 0.0073 & $<0.0001$ \\
\hline
\end{tabular}

$\mathrm{NA}=$ not applicable because these models did not demonstrate a significant step shift. $X=$ Components of the model (complete parameters available on request). ${ }^{\star}$ Month prior to intervention in (B): June 1985 for 4 and 5 year olds and September for those older than 5 years. + February 1994 in $(B)$. 
compatible. One possible explanation is that drivers with young passengers were more compliant with the law. Perhaps the social norms about child motor vehicle safety, reflected in CRD use, positively influence safety belt use for young children, particularly given the fact that many other states require that 4 and 5 year old children use CRDs. Adults who have child passengers already engage in safer driving habits than the general population of adult drivers. This may explain why the implementation of a mandatory safety belt law would have little effect on otherwise safe behavior in adults. ${ }^{19}$ In the face of safer driving habits of these adults, however, one would have expected higher belt use by the children in their care prior to the implementation of the law.

There are two possible explanations for the gradual effect of this law on passengers aged 6 through 15 years. One is that the law may have been associated with other changes in crash circumstances for these children. For example, there has been a gradual increase in the proportion of children who ride in the back seat, perhaps to avoid the use of safety belts. Children aged 6 through 15 were much more likely to have moved to the back seat than were younger children. Another explanation is changes in vehicle size - an important determinant of injury severity. Car size has gradually declined during the $1980 \mathrm{~s}$, but there is no reason to assume that the experience of smaller cars of older children would be different from that of younger children.

Our findings suggest three points for further study. First, more clearly targeted, rigorous observations and analyses of safety belt behavior in children are necessary to confirm that children actually use safety belts. Should observations reveal satisfactory levels of use, then a second line of investigation would involve further studies of the possible harmful effects of restraints. For example, circumstances associated with crashes in a rural environment such as North Carolina may differ from those in the urban setting reported by Agran et al. ${ }^{9} \mathrm{~A}$ third area of investigation would be to implement and evaluate efforts to improve the effectiveness of safety belts for this population, for example, through the use of booster seats. Further, it is appropriate to encourage and/or require CRD use for children up to the age of 5 years, instead of the present 3 years. CRDs are designed to be comfortable and effective for children up to 40 pounds, the median weight for 5 year olds.

\section{IMPLICATIONS FOR PREVENTION}

This study suggests that the safety belt law in North Carolina has been associated with a decline in the percentage of crash related deaths and serious injuries for children. To under- stand more thoroughly the mechanisms for this change, observational data and surveys on children's safety belt use should be collected routinely. In the interests of equity for children, ${ }^{20}$ policy makers should not assume that strategies that have an impact on adults will have a similar effect on children. As 'adult' injury control efforts expand, it is important to retain a categorical focus on the particular needs of children.

This research was supported by the Injury Prevention Research Center of the University of North Carolina and by Grant No MCJ-107 from the Maternal and Child Health Bureau (Title V, Social Security Act), Health Resources and Services Administration, Department of Health and Human Services.

1 Margolis L, Wagenaar A, Liu W. The effects of a mandatory child restraint law on injuries requiring hospitalization. child restraint law on injuries requiring

2 Wagenaar A, Webster D. Preventing injuries to children through compulsory automobile safety seat use. Pediatrics 1986; 78: 662-72.

3 Kahane C. An evaluation of child passenger safety. (DOT HS 806 890.) Springfield, Virginia: National Technical Information Service, 1986

4 Wagenaar A, Maybee RG, Sullivan KP. Mandatory seat belt laws in eight states: a time-series evaluation. $\mathcal{F}$ Safety $R e$ 1988; 19: $51-70$.

5 Chorba TL, Reinfurt D, Hulka B. Efficacy of mandatory seat-belt legislation. $\mathcal{F} A M A$ 1988; 260: 3593-7.

6 Rutherford WH, Greenfield AA, Hayes HRM, Nelson JK. The medical effects of seat belt legislation in the United Kingdom. London: HMSO, 1985.

7 Barancik J, Chatterjee B, Green-Cradden YC, et al. Motor vehicle trauma in northeastern Ohio, I: Incidence and vehicle trauma in northeastern Ohio, I: Incidence and Outcome by age, sex, and road

8 Burdi A, Huelke D, Snyder RG, Lowrey GH. Infants and children in the adult world of automobile safety design pediatric and anatomical considerations for design of child restraints. New York: American Society of Mechanical Engineers, 1970 .

9 Agran PF, Dunkie DE, Winn DG. Injuries to a sample of seatbelted children evaluated and treated in a hospital emergency room. $\mathcal{F}$ Trauma 1987 ; $27: 58-64$.

10 Osberg J, Di Scala C. Morbidity among pediatric motor vehicle crash victims: the effectiveness of seat belts. $A m \mathcal{F}$ Public Health 1992; 82: 422-5.

11 Hall W, Stewart JR. Effects of child passenger safety and seat belt legislation on fatalities and serious injuries to children involved in North Carolina crashes. 35th Annual Proceedings of the Association for the Advancement of ceedings of the Association for the Advancen

12 Popkin C, Campbell BJ, Hansen AR, Stewart RR. Analysis of the accuracy of the existing KABCO injury scale. Chapel Hill, NC: University of North Carolina Highway Safety Research Center, 1991.

13 Reinfurt DW, Campbell BJ, Stewart JR, Stutts JC. North Carolina's occupant restraint law: a three year evaluation. Chapel Hill, NC: University of North Carolina Highway Safety Research Center, 1988.

14 Hall W, Tolbert W, Cox C, Lowrance J. Comprehensive program for increasing use of safety seats and seat belts for
children and yound adults (final report). Chapel Hill, NC: children and yound adults (final report). Chapel Hill, NC: University of

15 Margolis LH, Kotch J, Lacey J. Children in alcohol-related motor vehicle crashes. Pediatrics 1986; 77: 870-2.

16 London School of Economics. Computer routine: ST AMP (Structural time series analyses, modeller and predictor). London: London School of Economics.

17 Harvey AC. Forecasting, structural time series models and the Kalman filter. Cambridge: Cambridge University Press, 1989.

18 Harvey AC, Durbin J. The effects of seat belt legislation on British road casualties: a case study in structural time series modelling. Fournal of the Royal Statistical Society (Series A) 1986; 149: 187-227.

19 Margolis LH, Wagenaar AC, Molnar LJ. Use and misuse of automobile child restraint devices. Am $\mathcal{F}$ Dis Child 1992; 146: $361-6$.

20 Margolis L, Runyan C. Accidental policy: an analysis of the problem of unintended injuries of childhood. $A m \mathscr{J}$ Orthopsychiatry 1983; 53: 629-44. 